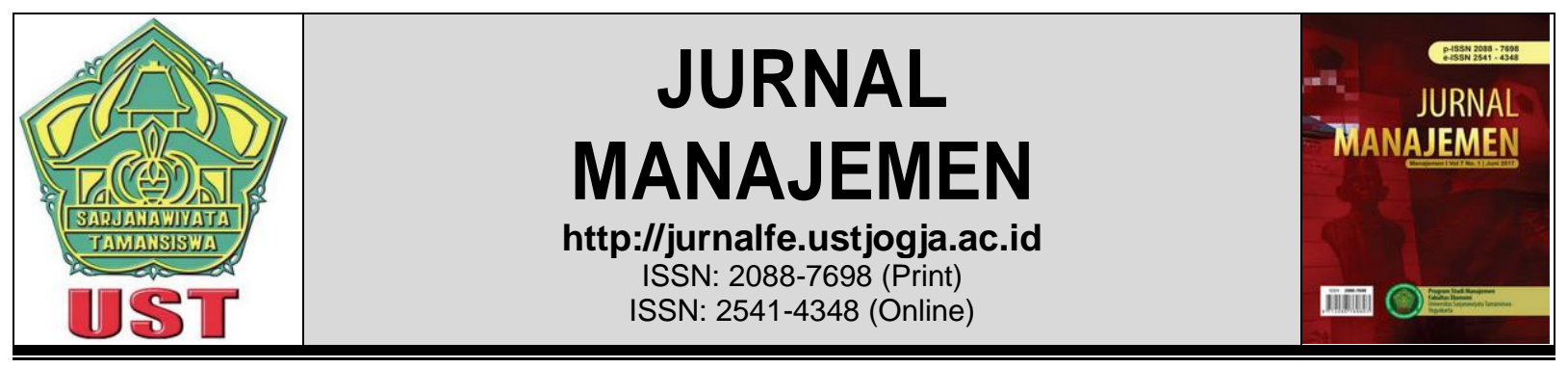

\title{
ANALISIS SWOT DESA WISATA DI KABUPATEN SLEMAN YOGYAKARTA
}

\author{
You She Melly Anne Dharasta ${ }^{1}$ \\ Dhiani Dyahjatmayanti ${ }^{2}$ \\ Kartika Fajar Nieamah ${ }^{3}$
}

\author{
${ }^{1,2,3}$ Sekolah Tinggi Teknologi Kedirgantaraan, Yogyakarta \\ Korespondensi: youshemelly@yahoo.co.id
}

\begin{tabular}{ll}
\hline Informasi Naskah & \multicolumn{1}{c}{ Abstrak } \\
\hline Diterima: & The purpose of this study(1) To analyze the threats, opportunities, \\
20 Oktober 2017 & strengths and weaknesses of each tourist village in Sleman in an \\
Revisi: & effort to increase tourist visits. (2) To know and analyze what \\
29 Oktober 2017 & tourism marketing strategy that can be applied in Sleman, \\
Terbit: & Yogyakarta. \\
1 Desember 2017 & From interviews with village tour managers and via \\
Kata Kunci: SWOT & questionnaires circulated to tourists, the average respondent \\
Analysis, Tourist & responded positively, although there were still things that were \\
Village, Sleman & perceived to be lacking, among others, access to transportation \\
& roads, parking lots, and road directions. \\
& Based on the SWOT analysis the most dominant strategy choice is \\
& the SO strategy (Strength Opportunities): the strategy utilizes all \\
& the power to create and utilize the greatest opportunities that is (1) \\
& Maintenance and development of the environment (2) Increase and \\
& multiply the tour package (3) Perform event to attract the tourists. \\
\hline
\end{tabular}

\section{PENDAHULUAN}

Yogyakarta yang memiliki lima kabupaten yaitu Kabupaten Sleman, Gunung Kidul, Kulon Progo, Bantul dan Yogyakarta, masing-masing kabupaten sedang mengembangkan potensi akan daerahnya yang bisa dijadikan obyek wisata. Perkembangan obyek wisata di Kabupaten Sleman sangat baik dalam kuantitas, maupun kualitasnya. Masing-masing obyek wisata mempunyai daya tarik tersendiri, mulai dari pegunungan, bendungan, sampai kolam renang beserta permainannya ada di dalamnya.

Pada saat ini, kabupaten Sleman sedang mengembangkan desa-desa yang masih sejuk dan alami yang berpotensi sebagai desa wisata. Desa wisata yang ada di Sleman diantaranya desa wisata Brayut, desa wisata Kelor, desa wisata Pentingsari, desa wisata Kembang Arum, desa wisata Pulesari, desa wisata Garongan, desa wista Tanjung, desa wisata Domes, desa wisata 
Nganggring, desa wisata Pancoh, dan lain-lain.

Dengan adanya desa-desa wisata ini diharapkan akan adanya pertumbuhan usaha dan ekonomi pariwisata yang meningkat. Dengan demikian perlu dipikirkan kebijaksanaan yang tepat dalam perencanaan pariwisata sebagai suatu industri. Sektor pariwisata ialah sektor yang sangat potensial untuk dikembangkan menjadi sektor andalan, karena berdampak luas dalam pembangunan berbagai sector serta diyakini sebagai sebuah industri masa depan yang mampu meningkatkan kualitas hidup masyarakat kearah yang lebih baik, dipercaya dapat meningkatkan devisa negara dan sekaligus memberikan kesempatan kerja bagi masyarakat setempat.

Namun demikian, pengelolaan pariwisata di berbagai daerah pada kenyataannya masih belum dilakukan secara optimal, oleh karena itu guna untuk mendukung pengelolaan pariwisata yang lebih baik maka perlu adanya penyusunan strategi pengembangan pariwisata untuk masing-masing desa wisata agar dapat digunakan untuk pembangunan pariwisata, di Kabupaten Sleman khususnya.

Pengembangan obyek wisata ini harus diikuti dengan pengelolaan yang baik serta pengenalan kepada masyarakat secara efektif dan efisien. Apabila pengunjung obyek wisata meningkat, maka akan berdampak pada pendapatan yang bertambah sehingga tidak kesulitan dalam menutup biaya-biaya yang digunakan untuk operasional obyek wisata. Oleh karena itu sangat penting disusun sebuah strategi pemasaran yang tepat, efektif, dan efisien.

Tujuan dari penelitian ini (1) Menganalisis ancaman, peluang, kekuatan dan kelemahan yang dimiliki oleh masing-masing desa wisata di Kabupaten Sleman dalam upaya meningkatkan kunjungan wisatawan. (2) Untuk mengetahui dan menganalis strategi pemasaran wisata apa yang dapat diterapkan di Kabupaten Sleman Yogyakarta.

\section{KAJIAN PUSTAKA DAN HIPOTESIS}

Analisis SWOT adalah identifikasi berbagai faktor untuk merumuskan strategi perusahaan.Analisis ini didasarkan pada logika yang dapat memaksimalkan kekuatan (strengts) dan peluang (opportunities), namun secara bersamaan dapat meminimalkan kelemahan (weakness) dan ancaman (threats).Keputusan strategis perusahaan perlu pertimbangan faktor internal yang mencakup kekuatan dan kelemahan maupun faktor eksternal yang mencakup peluang dan ancaman.Oleh karena itu perlu adanya pertimbanganpertimbangan penting untuk analisis SWOT (Rangkuti, 2006).

Matrik SWOT dapat menggambarkan secara jelas bagaimana peluang dan ancaman eksternal yang dihadapi perusahaan dapat disesuaikan dengan kekuatan dan kelemahan yang dimilikinya.Matrik SWOT sebagai alat pencocokan yang mengembangkan empat tipe strategi yaitu SO (menciptakan strategi yang menggunakan kekuatan untuk memanfaatkan peluang), WO (menciptakan strategi yang meminimalkan kelemahan untuk memanfaatkan peluang), ST (menciptakan strategi yang menggunakan kekuatan untuk mengatasi ancaman) dan WT (menciptakan strategi yang meminimalkan kelemahan dan menghindari ancaman).Perencanaan usaha yang baik dengan metode SWOT dirangkum dalam matrik (Rangkuti, 2006).

Kotler (2000) mengelompokkan faktor - faktor lingkungan eksternal sebagai bagian dari lingkungan makro, dan menambahkan aspek demografi dan alam kedalamnya.Kekuatan kekuatan yang ada didalam lingkungan makro ini tidak dapat dikendalikan dan harus dipantau serta ditanggapi oleh perusahaan karena lingkungan ini memberikan peluang sekaligus ancaman. Sementara itu David (2004) mengatakan bahwa lingkungan eksternal terdiri dari : (1) Kekuatan ekonomi; (2) Kekuatan sosial, budaya, demografi, dan lingkungan; (3) Kekuatan 
politik, pemerintah dan hukum; (4) Kekuatan teknologi; dan (5) Kekuatan kompetitif.

David (2004) mengatakan bahwa analisis lingkungan internal membutuhkan pengumpulan asimilasi, dan evaluasi tentang operasi perusahaan. Analisis internal berguna untuk mengetahui aspek kekuatan dan kelemahan yang merupakan faktor - faktor penentu keberhasilan (critical Succsess Factors).Hal ini juga disampaikan oleh Kertajaya (2005) yang mengatakan bahwa salah satu langkah dalam analisis internal dalam konteks daerah, adalah menentukan Critical Success Factors.

\section{METODE PENELITIAN}

Penelitian ini dilakukan di 10 (sepuluh) Desa Wisata di Kabupaten Sleman Yogyakarta. Metode penelitian yang digunakan adalah metode survey. Data yang dikumpulkan pada penelitian ini melalui: 1) Analisa Dokumen, 2) Observasi, 3) Wawancara. Teknik analisa data yang digunakan adalah analisis SWOT. Dalam proses pengambilan keputusan strategis selalu berkaitan dengan pengembangan misi, tujuan, stralegi dan kebijakan perusahaan. Dengan demikian perencanaan strategis harus menganalisa faktor-faktor strategis pemasaran wisata (kekuatan, kelemahan, peluang dan ancaman) dalam kondisi yang ada saat ini.Hal ini disebat dengan analisa situasi dan model yang paling popular untuk analisa situasi adalah SWOT.Ada tiga tahapan kegiatan yang harus dilakukan dalam analisa SWOT yaitu; (1) Pengumpulan Data, (2) Analisa Data, (3) Perumusan strategi.

Tahapan pokok tersebut dapat dijabarkan prosesnya ke dalain enam langkah yang pada akhirnya akin menghasilkan satu atau lebih goal strategi. Langkah tersebut antara lain:

1.Identifikasi kekuatan dan kelemahan di lingkungan internal,

2.Identifikasi peluang dan ancaman di lingkungan eksternal,

3.Penyusunan matrik faktor internal,

4.Penyusunan matrik faktor eksternal,

5. Tahap analisis,

Tahap penyusunan strategi.

\section{HASIL DAN PEMBAHASAN}

Sampel dalam penelitian ini adalah 10 (sepuluh) desa wisata di Kabupaten Sleman, Yogyakarta. Adapun profi dari masing-masing desa adalah sebagai berikut:

\section{Desa Wisata Tanjung}

Desa wisata Tanjung merupakan desa wisata yang meliputi tiga pedukuhan dalam wilayah Desa Donoharjo, Kecamatan Ngangklik, Kabupaten Sleman, Yogyakarta. tiga pedukuhan tersebut meliputi Pedukuhan Banteran, Pedukuhan Panasan, dan Pedukuhan Bantarjo. Secara geografis terletak diantara Gunung Merapi dengan Kota Yogyakarta. Pembentukan desa wisata Tanjung dilatarbelakangi pemikiran dan kenyataan bahwa para wisatawan yang berkunjung ke wilayah Yogyakarta sudah bosan dengan wisata konvensional. Desa wisata Tanjung merupakan desa wisata yang memiliki monumen budaya berupa Joglo Tanjung dan pola kehidupan masyarakatnya yang masih tradisional. Beberapa paket wisata ditawarkan merupakan wisata alam, karena alam desa Tanjung sangat sejuk dan rindang. Selain itu, Desa Wisata Tanjung menawarkan atraksi tarian tradisional Angguk Putri.

\section{Desa Wisata Brayut}

Di desa wisata Brayut, sawah ditawarkan untuk bermain, melepas lelah dan belajar menghargai kerja keras. Mulai dari membajak sawah dengan bajak yang ditarik oleh kerbau, atau menanam padi sambil bermain lumpur. Di desa ini tidak hanya akan belajar 
tentang bagaimana bertani, tetapi juga belajar beternak ikan, memasak makanan tradisional, memainkan gamelan atau berlatih menari dengan tarian tradisional desa ini. Bagi wisatawan yang hanya ingin menikmati suasana pedesaan sambil menginap, maka dapat menginap di penginapan dengan berbagai bentuk yang unik. Mulai yang paling sederhana sampai yang mewah. Pengelola desa wisata ini menyediakan cinderamata bagi wisatawan yang akan pulang. Pengelola telah menyediakan banyak cinderamata, mulai dari hiasan dinding sampai pada perabotan rumah tangga kuno dan alat permainan masa lalu seperti congklak.

\section{Desa Wisata Kembang Arum}

Desa wisata Kembang Arum lahir tahun 2005 atas gagasan bapak Heri Kustriyatno dari sanggar Pratista yang bekerja sama dengan warga setempat. Warga DWKA mengambil langkah baru menciptakan desa wisata berbasis pendidikan dengan nama "Desa Wisata Kembang Arum" dalam suatu tatanan yang apik, alami dan penuh dengan nilai ketradisionalan yang nantinya dapat mereka banggakan. Pada waktu pertama kali berdiri, DWKA serta menyediakan homestay sejumlah 55 buah, 3 buah gasebo, 1 rumah sawah yang digunakan sebagai tempat penginapan. Fasilitas yang diberkan oleh DWKA adalah masjid, homestay, arena permainan, sanggar lukis, perpustakaan wisata, mobil untuk jelajah alam dan rumah makan. Pada tahun 2008 desa wisata ini menjadi juara pertama lomba Desa Wisata Se Kabupaten Sleman. Kondisi geografinya terdiri dari pemukiman pedesaan, persawahan, perkebunan, sungai, parit dan tebing-tebing yang tidak begitu curam. Mayoritas penduduknya adalah petani salak, petani sawah dan wiraswasta lokal. Akses jalan di DWKA sangat mudah untuk dijangkau baik dengan kendaraan beroda dua maupun kendaraan beroda empat. DWKA berada ditepi jalan raya utama yang menghubungakn antara kota Yogyakarta dengan Kulon Progo. DWKA menyediakan berbagai macam paket yang ditawarkan kepada wisatawan, antara lain:

a. Wisata Pendidikan, meliputi wisata lukis, wisata batik, out bond, perfilman, dongeng, dan wisata lukis tokoh atau peristiwa dongeng sebelumnya.

b. Wisata Budaya, meliputi wayang kulit, musik, tari dan karawitan

c. Wisata Kuliner, meliputi pelayanan penyediaan jenis masakan tradisional

d. Wisata minuman tradisional, meliputi wedang teh, wedang jahe, wedang secang, wedang sere.

e. Wisata permainan tradisional, meliputi bentik, egrang, tulup, ceplokan dan gangsingan.

f. Wisata Alam dan Suasana meliputi sungai, sawah, kebun, tebing, parit, dan kicau burung.

g. Wisata pertanian (sawah), meliputi belajar menanam padi, membajak, menumbuk padi, cara panen padi, mencangkul.

h. Wisata perkebunan, meliputi menanam salak, memetik salak, belajar menanam singkong dan belajar menanam jagung.

i. Wisata perikanan, meliputi mencari ikan dan memancing ikan.

j. Wisata olahraga, meliputi renang di sungai atau parit dan outbond.

$\mathrm{k}$. Wisata peternakan, meliputi memberi makan kambing dan kelinci.

1. Wisata sekolah alam, meliputi belajar acting, belajar vokal, belajar presenter, belajar teater, belajar fortografi.

m. Wisata air, meliputi mandi di sungai dan berenang di kolam alam

n. Wisata ritual, meliputi ritual keagamaan, ritual suran, ritual ruwahan 
o. Wisata petualang, meliputi tracking menyusuri desa wisata, menyusuri sungai, tour motor trail ke lereng merapi

p. Wisata bakti sosial, meliputi baksos komunitas motor trail, kerja bakti komunitas motor trail

q. Wisata pemukiman, meliputi homestay atau gasebo, jogle sempor, griya sekar arum, gubug pereng, gubuk karouke, artshop.

\section{Desa Wisata Pulesari}

Desa wisata Pulesari merupakan desa wisata berada di kawasan pedesaan di lereng Gunung Merapi di daerah yang terkenal akan salak pondoh. Desa wisata ini menyajikan sebuah wisata alam dan budaya. Desa wisata ini bertujuan untuk memperdayakan SDM dan SDA yang ada agar eksistensi desa wisata ini dapat dikenal dan diakui oleh masyarakat luas sehingga bisa menjadi atraktif tersendiri bagi wisatawan yang hanya sekedar datang untuk menikmati suasana pedesaan yang ada di Pulesari ini. Desa wisata Pulesari merupakan desa wisata dengan ciri khas perkebunan salak pondoh. Oleh karena itu, desa wisata ini menyediakan museum salak sehingga pengunjung dapat mengetahui seluruh informasi mengenai salak.Museum salak ini merupakan sarana informasi untuk masyarakat umum mengenai salak.Selain untuk memenuhi kebutuhan ekonomi masyarakat Pulesari, museum salak ini didirikan bertujuan mampu memberikan informasi, edukasi, koleksi, dan inovasi. Museum salak ini diberi nama Museum Salak "Dewi Pule". Fasilitas yang diberikan di desa wisata Pulesari adalah layanan homestay yang berada di rumah warga sehingga wisatawan dapat berinteraksi langsung terhadap masyarakat. Selain itu wisatawan juga dapat menikmati masakan khas warga di homestay tempat mereka menginap. Desa wisata Pulesari juga menyediakan makanan khas salak untuk oleh-oleh, misalnya dodol salak, geplak salal, enting-enting salak, jenang salak, wingko salak, wajik salak, bakpia salak, nogosari salak, krupuk salak, sambal salak, dan karamel salak. Adapun minuman yang dapat dinikmati di desa wisata ini adalah jaesar, manisan salak, jaburan. Sedangkan kerajinan meliputi pembuatan keranjang salak, pembuatan kepang, belajar janur, dan membatik.

\section{Desa Wisata Kelor}

Desa wisata Kelor berada di wilayah desa Bangunkerto, Kecamatan Turi, Kabupaten Sleman, Propinsi Daerah Istimewa Yogyakarta. Suasana alam pedesaan diperkuat dengan adanya hamparan kebun salak, sungai yang jernih dan kolam ikan serta panorama gunung. Desa wisata Kelor memiliki beberapa icon wisata, diantaranya adalah kebun salak, makanan khas (sompil, nasi pondoh, tempe bacem), jelajah sungai bedhog, kolam ikan, dan arena outbound.

\section{Desa Wisata Nganggring}

Desa wisata Nganggring berada di Dusun Nganggring, Girikerto, Turi Sleman. Awal pengembangan desa Nganggring menjadi desa wisata sudah dikembangkan sejak tahun 2005 oleh masyarakat desa tersebut. Hal ini dikarenakan potensi wisata serta anugrah alam yang ada didesa mereka belum secara maksimal di manfaatkan. Potensi yang paling menonjol di desa ini adalah Peternakan Kambing dan perkebunan Salak. Dengan menjunjung tinggi budaya masyarakat pedusunan tersebut, serta kondisi alam yang sedemikian rupa menjadikan desa ini memiliki potensi wisata yang mengasyikan dan menyenangkan yang dikemas dalam bentuk paket yakni :

a. Paket keliling desa.

b. Paket Wisata Merapi 
You She Melly Anne Dharasta, dkk / Jurnal Manajemen. Vol 7, No 2 (2017): 42 - 50

c. Paket wisata kesenian tradisional, diantaranya adalah Hadroh, Shalawatan, Kubrosiswo, dan merti desa serta beberapa tarian jawa tradisional maupun kreasi modern.

d. Paket Wisata dolanan anak

e. Paket berkemah dengan kegiatan outbond serta tracking.

\section{Desa Wisata Pancoh}

Awal terkenalnya kawasan ini sebagai Ekowisata Desa ketika setelah terjadinya erupsi merapi pada tahun 2012 yang kemudian masyarkat sekitar membenahi kehidupan kembali dengan kegiatan wisata setelah beberapa penghasilan masyarakan kawasan menurun karena tejadinya kerusakan pada lahan pertanian, peternakan, perikanan dan perkebunan. Ekowisata Desa diabil untuk dijadikan nama wisata desa tersebut karena sesuai dengan visi dan misi pedukuhan Pancoh yang ingin melakukan kegiatan wisata berkesinambungan dengan mengedepankan kegiatan konservasi dalam ekologi dan sosial budaya yang bertujuan untuk meningkatkan perekonomian kawasan tersebut dan mensejahterakan rakyat. Desa Ekowisata Pancoh memiliki beberapa kegiatan pembelajaran, yaitu:

1. Belajar budidaya, seperti budidaya salak, ikan, beternak dengan pengolahan biogas, sayuran sehat dan tanaman hidroponik dengan teknik tradisional yang dilakukan warga Pancoh.

2. Belajar kebudayaan, seperti wiwit, nyadran, kenduri, njenangi, njenangi dan motoni masih sering dilakukan oleh masyarakat Pancoh yang dijadikan tradisi kehidupan masyarakatnya.

3. Belajar kesenian dan keterampilan, seperti karawitan, laras madya, bung beh, dan tari wireng yang berada pada tiap minggunya masih sering diadakan latihan rutin. Keterampilan yang dapat dilakukan seperti melukis caping, membatik, tata sungging wayang dan anyaman bambu.

4. Outbonddan fun game. Outbond dikemas dengan kegiatan yang biasanya sering dilakukan oleh masyarakat sekitar seperti membajak sawah, menanam padi, susur sungai, menangkap ikan, dan bermain di embung. Fun game dibuat dengan kemasan yang unik seperti permainan tradisional anak.

\section{Desa Wisata Garongan}

Desa Wisata Garongan berada di kaki Gunung Merapi menawarkan wisata pemandangan alam yang sangat indah, tracking sungai, perikanan, perkebunan dan out bond. Namun, desa wisata ini belum dikenal oleh banyak wisatawan karena keterbatasan

\section{Desa Wisata Pentingsari}

Desa wisata Pentingsari terletak di Pentingsari, Umbulharjo, Cangkringan, Sleman Yogyakarta.Desa wisata Pentingsari didirikan pada tahu 2008, yang dipelopori oleh Bapak Sumardi Wardisoekismo. Menurut bapak Wardisoekismo, awalnya masyarakat pentingsari tidak yakin kalau desa mereka mauakan dijadikan sebagai desa wisata. Tetapi lama kelamaan masyarakat mau menjadikan desa ini menjadi desa wisata karena keinginan kuat dari masyarakatnya. Untuk meningkatkan jumlah wisatawan, desa wisata Pentingsari banyak menawarkan produk-produk yang menarik, diantaranya adalah sebagai berikut Pancuran Suci Sendangsari, Rumah Joglo, Wisata Alam, Batu Persembahan, Ponteng, Jalur Tracking

\section{Desa Wisata Domes}

Di provinsi Yogyakarta terdapat sebuah perkampungan yang rumah penduduknya 
menyerupai rumah teletubies. Perkampungan ini dikenal dengan dengan nama kompleks rumah dome. Namun banyak juga orang menyebutnya dengan desa Teletubies. Hal ini dikerenakan semua bangunannya berbentuk dome/kubah. Rumah Domes ini pertama kali dibangun setelah pasca gempa yang melanda Daerah Istimewa Yogyakarta sebagai rumah yang tahan akan gempa. Bentuk rumah yang unik membuat kampung teletubies ini dikunjungi banyak wisatawan. Kebanyakan dari wisatawan banyak yang penasaran akan isi dari rumah dome tersebut. Jika dilihat dari luar, rumah Dome terlihat sanngat kecil, namun rumah tersebut memiliki beberapa ruangan, diantaranya adalah ruang tamu, dua ruang tidur dan dapur, dan juga rumah domes ini terdiri dari dua lantai. Selain rumah penduduk, kampung Domes ini juga terdapat beberapa fasilitas yang disediakan untuk wisatawan, diantaranya adalah mushola, piliklinik, dan aula pertemuan warga.Fasilitasfasilitas tersebuat semua bangunannya berbentuk kubah dengan ukuran yang lebih besar. Setiap hari minggu atau hari libur akan ada atraksi pertunjukan badut teletubies, sehingga wisatawan yang berkunjung bisa berpose bersama badut tersebut. Selain itu, wisatawan juga dapat naik kereta kelinci untuk berkeliling kampung Teletubies. Saat ini terdapat 80 rumah Domes, namun yang siap untuk menjadi homestay hanya 10 rumah dan dapat menampung kurang lebih 40 orang. Selain itu, berbagai paket wisata pun ditawarkan, mulai dari bersepeda mengelilingi perumahan, bermain permainan tradisional, melihat sunset dan dome's view, juga paket sunset dan sunrise selama dua hari satu malam. Saat ini desa wisata Domes juga memiliki layanan Jeep Wisata Shiva Adventure yang akan mengajak wisatawan menjelajah berbagai situs di kawasan ini seperti Tebing Breksi dan Candi Ijo dengan menggunakan jeep.

Berdasarkan profil dari masing-masing desa wisata, maka dapat dibuat analisis SWOT dan strategi yang dapat digunakan untuk meningkatkan jumlah kunjungan wisatawan, seperti tersaji pada Tabel 1.

Tabel 1. Analisis SWOT dan Usulan Strategi

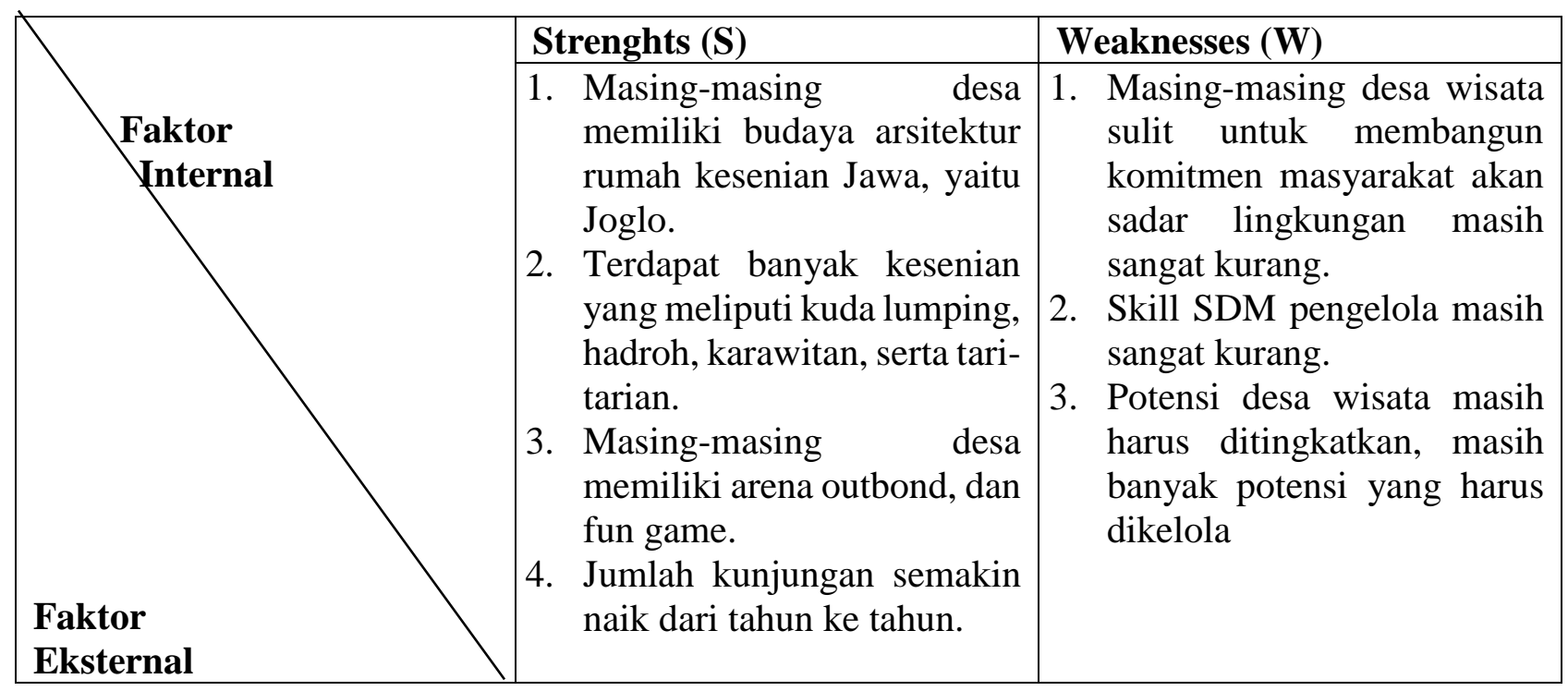




\begin{tabular}{|c|c|c|}
\hline Oppertunities (O) & $(\mathrm{S}-\mathrm{O})$ & $(\mathbf{W}-\mathrm{O})$ \\
\hline $\begin{array}{l}\text { 1. Menciptakan lapangan } \\
\text { kerja bagi warganya. } \\
\text { 2. Peluang meningkatkan } \\
\text { jumlah pengunjung sangat } \\
\text { besar }\end{array}$ & $\begin{array}{l}\text { 1. } \begin{array}{l}\text { Pemeliharaan dan } \\
\text { pengembangan lingkungan }\end{array} \\
\text { 2. } \begin{array}{l}\text { Meningkatkan dan } \\
\text { memperbanyak paket wisata }\end{array} \\
\text { 3. } \begin{array}{l}\text { Menyelenggaran event- } \\
\text { event untuk menarik para } \\
\text { wisatawan }\end{array}\end{array}$ & $\begin{array}{l}\text { 1. Menegakkan peraturan } \\
\text { kebersihan kepada seluruh } \\
\text { warga dan wisatawan. } \\
\text { 2. Memberikan pelatihan skill } \\
\text { kepada pengelola desa } \\
\text { wisata sehingga lebih } \\
\text { terampil dalam } \\
\text { 3. mengelola desa wisata. }\end{array}$ \\
\hline Threats (T) & $(\mathbf{S}-\mathrm{T})$ & $(\mathbf{W}-\mathbf{T})$ \\
\hline $\begin{array}{l}\text { 1. Ancaman bencana alam, } \\
\text { terutama letusan Gunung } \\
\text { Merapi yang akan } \\
\text { mengakibatkan kerusakan } \\
\text { pada desa wisata. } \\
\text { 2. Adanya desa wisata lain } \\
\text { yang letaknya saling } \\
\text { berdekatan sehingga akan } \\
\text { menimbulkan persaingan } \\
\text { yang cukup ketat. }\end{array}$ & $\begin{array}{l}\text { 1. Pemasangan tanda } \\
\text { peringatan bencana alam. } \\
\text { 2. Menonjolkan icon atau cirri } \\
\text { khas dari desa wisata } \\
\text { tersebut yang unggul dari } \\
\text { yang lainnya. }\end{array}$ & $\begin{array}{l}\text { 1. Selalu waspada akan } \\
\text { bencana alam. } \\
\text { 2. Mengajak masyarakat untuk } \\
\text { sadar akan desa wisata, } \\
\text { sehingga desa wisata } \\
\text { tersebut akan unggul dari } \\
\text { pada yang laiinya. }\end{array}$ \\
\hline
\end{tabular}

\section{PENUTUP}

Strategi yang dapat diambil dari hasil analisis SWOT yaitu strategi SO adalah strategi menggunakan kekuatan internal untuk memanfaatkan peluang-peluang yang ada di desa wisata yaitu:

a. Pemeliharaan dan pengembangan lingkungan

Pemeliharaan dan pengembangan lingkungan dengan meningkatkan potensi yang dimiliki oleh desa wisata tersebut, misalnya dengan menambah penghijauan, menambah pemeliharaan hewan ternak, penambahan tempat yang menarik untuk tempat berfoto, menambah jadwal pertunjukan adat atau kesenian daerah. Hal ini berarti desa wisata harus bisa memanfaatkan segala sesuatu yang ada di desa sehingga dapat meningkatkan daya tarik wisata.

b. Meningkatkan dan memperbanyak paket wisata,

Meningkatkan dan memperbanyak paket wisata dengan menambah berbagai jenis outbond mulai dari anak-anak hingga desawa, susur sungai, pemeliharaan hewan ternak (angon bebek, kambing, sapi, ternak ikan). penamba agar pengunjung lebih tertarik dan memiliki banyak pilihan paket wisata.

c. Menyelenggaran event-event untuk menarik para wisatawan. Dengan adanya event-event yang diselenggarakan maka akan menarik para wisatawan untuk mengunjungi desa wisata tersebut, misalnya atraksi jathilan, wayang, berbagai jenis tari Jawa, serta event panen hasil bumi. 


\section{Saran}

Berdasarkan kesimpulan di atas, maka saran yang dapat diberikan untuk meningkatkan kunjungan wisatawan di desa wisata Kabupaten Sleman adalah sebagai berikut.

1. Pelebaran akses jalan sehingga bus besar dapat masuk dengan leluasa di lokasi desa wisata Kabupaten Sleman

2. Penambahan SDM dibidang pemasaran untuk meningkatkan promosi paket wisata.

3. Perlunya alat untuk promosi sehingga menarik kunjungan wisatawan, contohnya brosur wisata yang menarik.

4. Periklana sebaiknya dilakukan via online.

5. Peningkatan sarana pendukung desa wisata, seperti kedai makan khas desa serta kedai souvenir.

\section{REFERENSI}

Cooper, D. R., \& Schindler, P. S. (2011). Business research methods. McGraw Hill : Singapore.

Kertajaya H, dkk. 2005. Attracting Tourist, Trader, Investors : Strategi memasarkan daerah diera otonomi. Jakarta : MarkPlus\&Co.

Kotler P. 2000.Manajemen Pemasaran, Jilid 1, edisi Millenium. Hendra teguh, Ronny A Rusli dan Benyamin Molan. Penerjemah.Jakarta : PT Prenhallindo. Terjemahan Dari Buku :Marketing Management. . 2000. Manajemen Pemasaran, Jilid II, Edisi Millenium. Hendra Teguh, Ronny A Rusli dan Benyamin Molan. Penerjemah.Jakarta : PT Prenhallindo. Terjemahan Dari Buku :Marketing Management.

Porter, M.E. 1985. Competitive Advantage. New York: Free Press.

Porter, Michael E \& Maulana, Agus.(1997). Strategi Bersaing Teknik MenganalisisIndustri dan Pesaing.Edisi Bahasa Indonesia. Jakarta: Penerbit Erlangga

Rangkuti, F. 2006. Analisis SWOT Teknik Membedah Kasus Bisnis. Jakarta: PT. Gramedia Pustaka Utama.

Syafei, Firman. 2007. Analisis StrategiPemasaran Pariwisata Bahari Taman Nasional Laut Kepualauan Seribu.[Skripsi].Bogor : Institut Pertanian Bogor.

Thompson, A. A., Peteraf, M. A., Gamble, J. E., \& Strickland, A. (2012).Crafting and ExecutingStrategy The Quest For Competitive Advantage Concepts and Cases Eighteenth Edition.New York: McGraw-Hill. 